\title{
INTERAÇÃO ENTRE PARES E DIÁLOGO NA ESCOLA: POSSIBILIDADES PARA MELHORAR A ESCOLA DO SÉCULO XXI.
}

\author{
Carmen Lúcia Dias, Jeong Cir Deborah Zaduski, Verônica Nogueira Vanni \\ Universidade do Oeste Paulista - UNOESTE, Presidente Prudente, SP. E-mail: kkaludias@gmail.com, \\ deborah_zaduski@hotmail.com, veronica_vanni@hotmail.com.
}

\section{RESUMO}

O presente trabalho pretende discutir alguns pressupostos fundamentais sobre a importância da interação entre pares na escola e do diálogo enquanto forma de comunicação não violenta tendo em vista que estes mecanismos podem ser usados pela escola tanto no auxílio à produção do conhecimento quanto na busca pela formação social e moral dos indivíduos. Pretende-se, com estas reflexões, resgatar dois dos quatro pilares fundamentais da Educação, ressaltados pela UNESCO, o de aprender a ser e o de aprender a conviver, pois acreditamos que a promoção do diálogo é uma peça fundamental para este processo e, as assembleias de classe são uma alternativa viável, interessante e eficaz para dar voz aos alunos e promover o ensino/aprendizagem. A pesquisa é de cunho qualitativo, analisando as principais teorias que abordam a temática proposta, comparando a teoria com as vivências práticas experienciadas pelas pesquisadoras. Como resultado podemos afirmar que o uso das assembleias de classe é uma prática que, se elaborada de modo significativo e sistematizado, contribui com a formação moral e, pode fomentar o desenvolvimento intelectual e social dos alunos.

Palavras-chave: Interação entre pares; Assembleias de classe; Desenvolvimento intelectual e social; Autonomia.

\section{PEER'S INTERACTION AND DIALOGUE IN SCHOOL: POSSIBILITIES TO IMPROVE THE SCHOOL OF THE XXI CENTURY}

\begin{abstract}
This paper aims to discuss some fundamental assumptions about the importance of interaction among peers at school and the dialogue as a non-violent form of communication, having in mind that these mechanisms can be used by the school both in helping the production of knowledge as, in the pursuit of social and moral formation of individuals. It is intended with these reflections, to redeem two of the four pillars of education, which were highlighted by UNESCO: learning to be and learning to live together. We believe that the promotion of dialogue is a key part of this process and the class assemblies are a viable, interesting and effective alternative to give voice to the students and promote the teaching / learning process. The research has a qualitative approach, analyzing the main theories that address the proposed theme, comparing the theories with the practical experiences lived by the researchers. As a result we can say that the use of class assemblies is a practice that, if developed in a significant and systematic way, contributes to the moral formation and can foster the intellectual and social development of students.

Keywords: peer's interaction; class assemblies; intellectual and social development; autonomy.
\end{abstract}

\section{INTRODUÇÃO}

Estamos na era digital e as discussões sobre o uso das tecnologias dentro e fora da sala de aula é recorrente em simpósios, conferências, seminários ou reuniões pedagógicas. Muitos se preocupam sobre o uso ou não das tecnologias digitais em sala de aula pois, apesar dos benefícios verificados em diversas situações, também existem professores que são contra o uso de celulares e tablets afirmando que os alunos não respeitam as regras e não sabem o momento correto de utilizar as tecnologias.

Nesse sentido, acreditamos que antes de discutir sobre o uso das tecnologias em sala de 
aula, é fundamental refletir sobre o ambiente escolar, sobre como são determinadas as regras e códigos de ética e conduta que regem determinado espaço de convivência, verificando se os alunos puderam participar deste processo, legitimando ou refutando as escolhas e dialogando sobre as diversas possibilidades, ou se, ao contrário, regras, limites e convenções foram determinadas a funcionários e alunos, sem flexibilidade, em caráter impositivo e autoritário, cabendo à todos obediência e respeito.

A assembleia de classe é um momento de reunião e discussão entre os alunos com a mediação de um professor. É um espaço no qual é possível dialogar e interagir livremente conversando sobre ideias, regras e sugestões para melhorar o convívio social e as práticas escolares. Neste espaço, no qual todos têm vez e voz, é possível colocar em pauta desde os problemas enfrentados pelos alunos no quotidiano da sala de aula, quanto problemas relativos à escola ou a comunidade. Segundo Freire (1987):

O diálogo é o encontro
entre os homens,
mediatizados pelo mundo,
para designá-lo. Se ao
dizer suas palavras, ao
chamar ao mundo, os
homens o transformam, o
diálogo impõe-se como o
caminho pelo qual os
homens encontram seu
significador enquanto
homens; o diálogo é, pois,
uma necessidade
existencial. (FREIRE, 1987,
p. 42).

Freire é reconhecido internacionalmente por seu modelo de educação progressista que considera o aluno enquanto construtor de seu próprio conhecimento. Para o autor, o aluno deve ser respeitado e valorizado e, o professor deve ser um mediador no processo de aprendizagem do aluno, levando sempre em consideração o conhecimento prévio deste, em busca de um ensino/aprendizagem significativo e para toda a vida. Nesse sentido, o diálogo, o respeito e, a valorização do outro, são peças chaves para um ensino/aprendizagem de qualidade, contrariamente ao que Feire chamou de educação bancária, àquela na qual o professor é transmissor do conhecimento e o aluno deve decorar o conteúdo, sem refletir ou questionar sobre o que lhe foi dito.

Freire (2002) ressalta ainda a importância de se implantar uma educação alicerçada nas interações entre os alunos, para o estabelecimento de um diálogo entre eles e, o consequente desenvolvimento do pensamento crítico. Segundo o autor, uma educação autêntica é àquela que tem como base o diálogo.

Nesta mesma linha de pensamento, valorizando a interação entre os pares e o diálogo, Pontecorvo, Ajello e Zucchermaglio (2005), abordam a construção do conhecimento fundamentada em um modelo construtivista e interacionista, tendo como base a discussão, o confronto de opiniões, a produção de argumentações e a negociação com os outros, enquanto elementos fundamentais para a construção de significados em comum e, consequentemente, para a transmissão e construção do conhecimento.

As autoras ressaltam ainda que 0 desenvolvimento ocorre sempre no contexto de uma cultura, em um contexto social e através da comunicação e da troca interpessoal e, na ausência de possibilidades de mediações efetivas, educacionais e socioculturais, o desenvolvimento não seria possível. Segundo Bruner (1996), o homem se desenvolve à medida em que apreende os conceitos presentes na sociedade na qual está inserido.

O desenvolvimento do
homem é um processo de
interiorização dos modos
de agir, imaginar,
simbolizar, que existem na
sua cultura, modos que
amplificam os seus
poderes. Portanto, ele
desenvolve esses poderes
de uma maneira que
reflete os usos aos quais
lhe destina a cultura a que
pertence. (BRUNER, 1996,
p. 22).

Ainda neste sentido, para Vygotsky (1974) é através da interação que são construídos os signos e os símbolos que farão parte do repertório de conceitos utilizados pela criança para ser e compreender a si mesma enquanto parte da sociedade. Para fundamentar como ocorre a construção do conhecimento, o autor traz dois conceitos importantes, ou seja, a 
interiorização e, as interações que ocorrem na zona de desenvolvimento proximal (ZDP).

A ZDP é a área na qual é possível a realização de um novo desafio, tarefa ou atividade, permitindo ao indivíduo que atinja níveis superiores de desenvolvimento (zona de desenvolvimento potencial) e vá além de suas capacidades atuais (zona de desenvolvimento real), por meio do auxílio de outra pessoa. É importante salientar que este auxílio externo não precisa necessariamente partir de um adulto, podendo tratar-se da troca ou interação entre os próprios estudantes, que focalizam diferentes perspectivas sobre o mesmo problema, e podem assim diversificar sua visão e compreensão sobre temáticas variadas.

Já o conceito de interiorização, é apresentado em Vygotsky, como um movimento que parte de fora para dentro, ou seja, é a partir do momento que o indivíduo interage com os outros que é possível a transformação e modificação de conceitos, signos e símbolos, pois neste processo de troca, ao confrontar as ideias com as do outro, pode-se aceitar, refutar ou modificar os pensamentos iniciais reforçando estruturas mentais ou criando novas.

O conceito da zona de desenvolvimento proximal, apesar de enraizado na psicologia, é muito conhecido e utilizado entre educadores por ressaltar a importância da interação, no processo de aprendizado. Segundo Vygotsky (1999):

Um aspecto essencial do aprendizado é o fato de ele criar a zona de desenvolvimento

proximal; ou seja, o aprendizado desperta vários processos internos de desenvolvimento, que são capazes de operar somente quando a criança interage com pessoas em seu ambiente e quando em cooperação com companheiros. Uma vez internalizados, esses processos tornam-se parte das aquisições do desenvolvimento da criança. (VYGOTSKY, 1999, p. 117-118).

Destarte, consideramos fundamental a inter-relação entre o desenvolvimento individual e social no sentido da indispensável interação para a construção e organização do conhecimento, tendo em vista que o indivíduo compreende o mundo ao seu redor e a realidade na qual está inserido através das relações que estabelece.

Sendo a escola, após a instituição familiar, local onde o aluno entra em contato com outras culturas, valores e histórias de vida diferentes da sua, faz se necessário que a integração social se estabeleça de forma harmoniosa para que, no convívio diário entre pares e em grupo, as trocas de aprendizagens sejam favorecidas, pois, é também por meio delas que os alunos poderão evoluir, tanto na construção de conhecimentos cognitivos, quanto morais e sociais.

A preparação para uma participação ativa na vida de cidadão tornou-se para a educação uma missão de caráter geral, uma vez que os princípios democráticos se expandiram pelo mundo. (DELORS, 1996, p. 61).

Desta forma, a escola necessita oferecer em seu interior, além de um espaço para aprendizagens cognitivas, trocas de vivências e experiências, nas quais estes alunos possam dividir conhecimentos, trajetórias de vida individuais e somar a esta elementos que transformem o seu pensar e agir, modificando o seu comportamento perante o outro, desenvolvendo habilidades necessárias para o convívio social, como aponta Delors "Aprender a viver juntos, aprender a viver com os outros". (DELORS, 1996, p. 96).

\footnotetext{
Nossa época reclama claramente uma urgência maior: ensinar e aprender a viver em sociedade. Essa tarefa exige uma revolução sociopsicológica e pedagógica que ainda está por se realizar. O horizonte educativo deve ser o de promover a autonomia do aluno, não só nos aspectos cognitivos, mas também seu desenvolvimento moral e social. (MORENO, 2005, p. 94).
}

Neste sentido, no incentivo ao diálogo, a escola deve proporcionar aos alunos a 
oportunidade de se expressar, colocar seu ponto de vista e respeitar e ouvir os outros, aprendendo sobre quais são os valores necessários para o convívio agradável e harmonioso no ambiente escolar. Tendo em vista um dos pressupostos centrais da educação, ou seja, o desenvolvimento da autonomia do aluno, é necessário que sejam planejados momentos que favoreçam o diálogo e a interação entre pares, contribuindo no desenvolvimento de capacidades e habilidades necessárias para a convivência em sociedade.

Finalmente vale ressaltar que a prática das assembleias, sobre a qual discutimos neste estudo, em um convite à reflexão sobre a importância da comunicação dialógica, abrange os preceitos da comunicação não violenta que segundo Rosenberg (2006) é um diálogo no qual é considerado o contexto e, é necessário externalizar as emoções vividas ao ouvir o outro, em um exercício de verbalização de sentimentos e de escuta empática, evitando assim ruídos, falta de entendimento e uma interpretação errada das mensagens. $O$ autor relata uma série de exercícios que podem ser feitos para que a mensagem enviada pelo emissor (aquele que fala) seja recebida corretamente pelo receptor (quem ouve). Isso é muito importante, pois, nem sempre percebemos o efeito que nosso diálogo provoca no outro, originando problemas dos quais muitas vezes não temos ciência, pois, só o outro pode dizer o efeito que palavras e expressões tiveram para ele.

Contudo, este trabalho não pretende ter como foco recomendações específicas para a prática das assembleias em sala de aula, tendo em vista que não existe uma receita mágica de sucesso para que ela funcione igualmente em salas de aula diversas. Acreditamos que 0 professor em conjunto com alunos e gestores, devam ser os autores e sujeitos ativos no processo decisório, já que cada situação e cada contexto exigem determinadas ações e, ninguém melhor do que os próprios sujeitos, para reconhecer e determinar quais são as práticas mais eficazes e significativas naquele contexto. Assim sendo, passamos aos objetivos que compõem este estudo.

\section{OBJETIVOS}

Este trabalho tem como objetivo a discussão crítico-reflexiva sobre a importância da promoção do diálogo na escola por meio da criação de um espaço aberto, no qual seja possivel tanto a expressão de opiniões, quanto a criação em conjunto de regras e, o compartilhar de ideias para a construção do conhecimento. A prática que será abordada neste estudo é a promoção de assembleias de classe, enquanto uma das possibilidades possíveis para a interação entre pares e troca colaborativa. O motivo de tal escolha se justifica, tanto pela experiência de uma das pesquisadoras, a qual utiliza esta prática em seu ambiente de trabalho, quanto pela facilidade existente para a sua implementação, considerando-se que não é necessário o uso de estruturas externas, material de apoio ou qualquer aparelho ou estrutura tecnológica para que todo o processo funcione corretamente. Este fator é de grande importância pois, infelizmente, ainda presenciamos em uma grande parte das escolas e instituições de ensino uma total falta de estrutura física, tecnológica ou intelectual para que sejam desenvolvidas e implementadas mudanças nas práticas escolares.

\section{METODOLOGIA}

Esta pesquisa bibliográfica (SALVADOR, 1991), teve como aporte teórico a revisão de literatura especializada para a temática, com autores que tratam sobre o desenvolvimento da aprendizagem, a promoção do diálogo no ambiente escolar, o desenvolvimento humano, e a interação entre pares, os quais contribuíram para reflexões enriquecedoras sobre quais mecanismos podem ser utilizados na escola para compreender melhor os alunos e amenizar os problemas encontrados, dando espaço para que os próprios alunos possam participar da construção dos valores e princípios que regem o ambiente escolar, agregando significado ao que é aprendido e ensinado.

Nessa ótica, faremos a seguir algumas reflexões sobre a comunicação dialógica e seus pressupostos fundamentais.

\section{A comunicação dialógica para a superação de problemas escolares}

A ação pedagógica na escola implica necessariamente em um processo de aquisição e de troca cultural, de experiências e, pontos de vista. De acordo com Vygotsky (1974) é por meio da linguagem e, portanto, da fala, que estas interações ocorrerem, permitindo que o conhecimento seja construído a partir das relações interpessoais estabelecidas. Outrossim, pode-se afirmar que é a partir das interações e da comunicação entre os sujeitos que são construídos novos conhecimentos, ou ainda, são 
aprimorados os conhecimentos que já existem, ou seja, o diálogo viabiliza a ampliação dos aspectos cognitivos e sociais, fortalecendo e ampliando a capacidade do ser humano em refletir, interagir e posicionar-se de forma coerente na sociedade.

O diálogo permite ainda, o estabelecimento de relações democráticas, por meio de relações mais igualitárias e menos unilaterais nas salas de aula, favorecendo relações mais humanas e harmoniosas, com respeito mútuo entre professores e alunos, assim como entre alunos.

\begin{abstract}
O diálogo é a relação de um "eu" frente a um "tu". Pressupões, portanto, a existência de saberes nos dois sujeitos que compõe os polos da relação. O confronto de saberes, porém, requer dos sujeitos a partilha da palavra e a concessão de que seus saberes não são absolutos. (FÁVERO, 2002, p.14).
\end{abstract}

Um aspecto importante a ser ressaltado em Favero (2002) é a necessidade presente na relação dialógica de reconhecer o outro enquanto parte fundamental neste processo interativo. Este exercício de ser ouvido, mas também, de saber ouvir, implica no respeito pelos saberes alheios, mesmo que estes sejam diferentes ou contrários ao convencional ou ao considerado normal ou correto.

Assim, o diálogo é importante na formação do indivíduo, uma vez que este, durante a interação como outro, ao comunicarse, constrói-se a partir da troca de pontos de vista enquanto sujeito de sua própria história, conforme ressalta Bakhtin (2002):

A comunicação verbal,
inseparável das outras
formas de comunicação,
implica conflitos, relações
de dominação e de
resistência, adaptação ou
resistência à hierarquia,
utilização da linguagem
pela classe dominante
para reforçar seu poder,
etc. (BAKHTIN, 2002,
p.14).

Bakhtin (2002) reforça a ideia de que o diálogo nem sempre se dá enquanto um reforço de crenças e de estruturas mentais preexistentes, com a associação de ideias entre pessoas que compartilham da mesma linha de pensamento. A riqueza e a beleza do diálogo está, também, no confronto, na possibilidade do questionamento das relações de poder, em busca da superação das relações dominantes, resolvendo conflitos e discutindo as relações de poder presentes na sociedade.

Desta forma, pode-se refletir o quanto a comunicação verbal é de extrema valia na sala de aula. É por meio das relações dialógicas que é possível confrontar ideias, expor experiências, explicitar dúvidas, afinando as ideias com seus pares no contexto no qual está inserido, por intermédio do ato que o diálogo promove, que é o de falar, mas também ouvir o outro.

Ainda que não seja a escola o único ambiente de aprendizagem no qual podem ocorrer relações dialógicas a partir de debates e trocas de ideias possibilitadas graças a comunicação e a interação do sujeito com o meio, ela é, o lócus privilegiado para proporcionar inúmeras possibilidades significativas de interação, de trocas de experiências construtivas com a finalidade de facilitar o desenvolvimento intelectual e a construção de conhecimentos cognitivos.

Fontana (2000) reforça esta ideia, destacando a palavra como fonte que permite ao sujeito a possibilidade de situar-se em um contexto, imprimir significados, elaborar e nortear suas operações mentais, construindo novos conceitos e consequentemente ampliando sua capacidade mental.

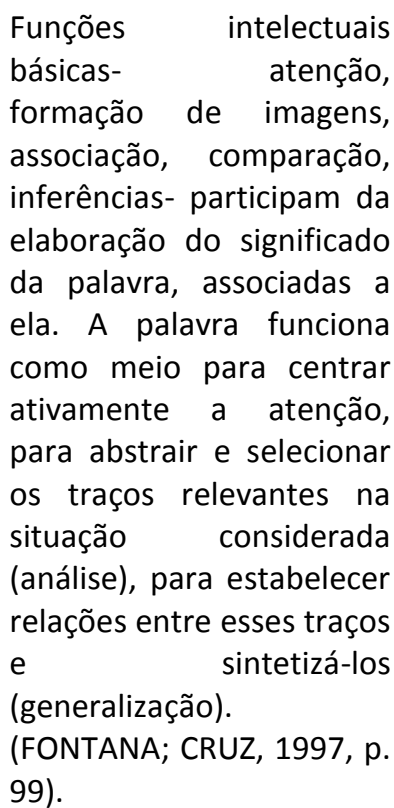


O diálogo é, portanto, fonte rica no fornecimento de elementos para a construção de conceitos e ideias de forma não reducionista, pois a partir de uma perspectiva, integram-se novas percepções oriundas do outro, expandindo a possibilidade de reflexão, promovendo conclusões mais coerentes e plurais.

Para Freire (1987) a humanização das pessoas é uma das finalidades da educação e, este processo está intrinsecamente relacionado com o diálogo, tendo em vista que ele é uma possibilidade real para a construção democrática da relação professor- aluno, partindo dos pressupostos de uma educação problematizadora, que visa a transformação das relações de opressão em relações democráticas, de solidariedade, respeito e amor ao próximo.

Uma educação humanizadora, segundo Freire (1987) tem como base o diálogo interpessoal, sendo composta por duas dimensões: a ação, ou ato da fala enquanto direito irrefutável de homens e mulheres e condição para a não alienação e; a reflexão, atrelada à conscientização crítica e não alienante, ou seja, o ouvir atentamente, criticamente, sem aceitar as verdades ditas pelo outro, sem uma reflexão do que foi dito. Para o autor, "Os homens se fazem pela palavra, no trabalho, na ação-reflexão". (FREIRE, 1987, p. 78).

Segundo Freire (1987) o diálogo é o caminho para que o professor conheça o aluno e, para que seja estabelecida uma relação capaz de romper com os esquemas verticais característicos da educação bancária, superando as relações de superioridade e inferioridade e as contradições muitas vezes presentes no diálogo entre educador e educando, para ele:

(...) o educador já não é o que apenas educa, mas o que, enquanto educa, é educado, em diálogo com o educando que, ao ser educado, também educa. Ambos, assim, se tornam sujeitos do processo em que crescem junto e em que os "argumentos de autoridade" já, não valem. (FREIRE, 1987, p. 39).

Neste ideal de educação libertadora, proposta por Freire (1987) educador e educando são sujeitos em um processo no qual ocorrem concomitantemente ensino e aprendizagem tanto originados pelo professor quando pelo aluno, graças a uma relação dialógica de respeito e valorização do outro enquanto ser humano capaz e, portador de conhecimentos, fazendo com que neste cenário educativo, a construção dos saberes seja realizada de forma conjunta.

Oliveira e Santos (2007) refletem sobre a importância do respeito ao outro na comunicação dialógica, tendo em vista que a igualdade propagada por Freire não está em anular-se ou mascarar suas características individuais para concordar ou igualar-se ao outro, e sim, em compreender e respeitar as diferenças, refletindo criticamente sobre pontos de vista divergentes, sem que seja necessário convalidar crenças e ideais para conviver em união. Segundo os autores:

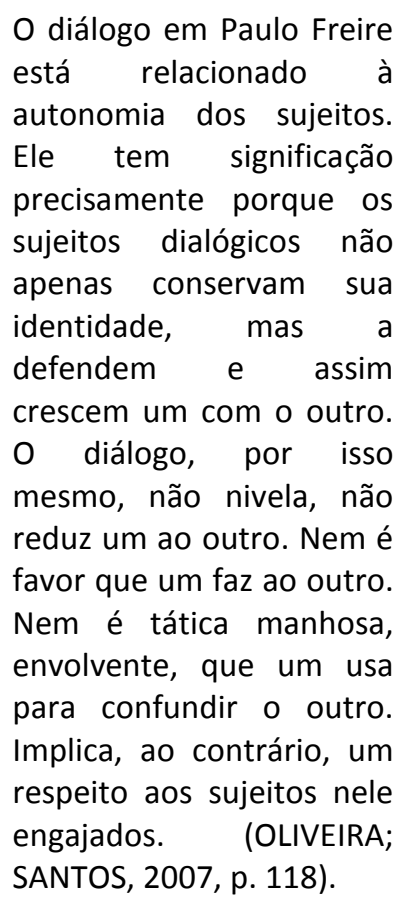

Nesse sentido, tendo em vista as possibilidades de crescimento e de desenvolvimento dos alunos, possibilitadas por meio de relações dialógicas organizadas de forma a possibilitar a todos o direito de falar e a importância de saber ouvir, propomos a prática das assembleias de classe, enquanto momento oportuno de troca colaborativa, considerando-se que a organização de um espaço propício para esta prática pode garantir igualdade de voz e vez, dando autonomia a todos os alunos para participarem deste processo colaborativo.

\section{Assembleias: um espaço para a diálogo}

A assembleia de classe é um instrumento educacional que o professor pode valer-se na intencionalidade de potencializar em momentos organizados de forma sistemática para o seu 
desenvolvimento, a participação dos indivíduos em questões que perpassam o universo escolar e que necessitam de deliberação de forma reflexiva, crítica e coletiva.

[...] informações são transmitidas, situações são analisadas, a vida do grupo é organizada e decisões que afetam seus membros são tomadas. São funções desenvolvidas mediante a consideração de temas muito variados, reconhecidos pelo grupo como especialmente significativos. (GARCIA; PUIG, 2010, p. 74).

Ressaltamos em Garcia e Puig (2010) o fato de que os assuntos escolhidos para averbação durante a assembleia de classe partem dos próprios estudantes, a partir de suas vivencias, dúvidas e necessidades, sendo, portanto, significativo por tratar de assuntos relativos ao contexto no qual eles estão inseridos, seja ele a escola, a comunidade, a cidade ou o país. Ainda, buscando definir as assembleias Araújo (2002) destaca que:

[...] as assembleias são o momento institucional da palavra e do diálogo. 0 momento em que o coletivo se reúne para refletir, tomar consciência de si mesmo e transformar tudo aquilo que os seus membros consideram oportuno. E um momento organizado para que alunos e alunas, professores e professoras possam falar das questões que lhes pareçam pertinentes para melhorar o trabalho e convivência escolar. (ARAÚJO, 2004, p. 22).

Nesse sentido, podemos afirmar a potencialidade da prática das assembleias enquanto aliadas na resolução de problemas encontrados tanto na escola, no âmbito relacional entre alunos e, entre alunos e professores ou gestores, quanto na comunidade. Um exemplo, que poderia ser discutido, em ocasião das assembleias, trata-se da atual epidemia de dengue; o que a escola poderia fazer para conscientizar o bairro ou a comunidade na qual está inserida para que a população trabalhe em conjunto com a escola no combate ao mosquito aedes aegypti? Certamente este é apenas um exemplo das muitas questões que podem ser discutidas neste momento propício para o diálogo e para a troca colaborativa discutindo, inclusive, sobre os problemas que afetam direta ou indiretamente a escola e a comunidade.

Além, como completa Argüís (2002), a prática das assembleias escolares também pode servir como um dos mecanismos disponíveis para a educação moral, considerando-se que é de grande contribuição no estímulo e na promoção do protagonismo do indivíduo, bem como na preparação de sua participação enquanto cidadão da sociedade.

As assembleias escolares
são um espaço de
educação moral, porque
nelas introjetam-se
valores como respeito, a
colaboração, a
solidariedade ou a justiça,
e exercem-se capacidades
psicomorais, como a
empatia, o diálogo, a
compreensão, o juízo ou a
autorregulação
(ARGÜÍs, 2002, p...]. 28).

O momento das assembleias oportuniza o envolvimento e a participação de todos, professores e alunos e pode ser estimulada a atuação até mesmo daqueles alunos mais tímidos e que geralmente não se manifestam durante as aulas, uma vez que a comunicação é estruturada para que ocorra de forma respeitosa, o que favorece a promoção de um ambiente democrático na escola.

O modelo das assembleias
é o da democracia
participativa, que tenta
trazer para o espaço
coletivo a reflexão sobre
os fatos cotidianos,
incentivando r os
protagonismos
pessoas das
participação do grupo na
busca de
encaminhamentos para os
temas abordados,
respeitando
naturalizando


diferenças inerentes aos valores, às crenças e aos desejos de todos os membros que delas participam. (ARAÚJO, 2004, p.24).

Valer-se das assembleias de classe como mecanismo de educação moral e enquanto uma prática permanente, é uma valorosa oportunidade aos alunos no contexto escolar, uma vez que no exercício do diálogo, da reflexão em conjunto, na externalização dos sentimentos próprios e na escuta dos sentimentos e pontos de vista do outro, pratica-se o respeito, a criticidade e o amor ao próximo. Além disso, este recurso contribui não só para o desenvolvimento cognitivo/ intelectual mas também para a construção sociomoral, propiciando uma melhoria na qualidade das relações interpessoais dos sujeitos envolvidos.

Destarte, as reflexões propiciadas por meio das assembleias devem ser consideradas como um recurso a ser valorizado no ambiente escolar, não só em sala de aula, mas também nos demais segmentos da escola para que ocorra uma aprendizagem democrática em conjunto com professores, gestores e funcionários. No entanto, é necessário que não sejam consideradas apenas as assembleias de classe para que se atinjam as metas propostas neste trabalho. Em busca da promoção do diálogo, da valorização do outro e do respeito, é imprescindível que educador e equipe escolar constantemente desenvolvam estratégias diversificadas na intencionalidade de propiciar oportunidades para que os alunos possam manifestar-se por meio de discussões coletivas e procurem soluções para as questões que surgem no cotidiano da escola.

Assembleias não são 'mágicas' ou panaceias que resolverão todos os problemas. É preciso cautela com falsas expectativas de que 0 objetivo destas seja a eliminação dos problemas. São, na verdade, mais uma possibilidade de resolução de conflitos e uma oportunidade para que crianças e adolescentes se sintam pertencentes ao grupo e responsáveis por este. É verdade, portanto, que, se são uma das possibilidades, haverá outras estratégias a serem realizadas decorrentes de um ambiente cooperativo. (TOGNETTA; VINHA, 2007, p. 100).

Desta forma, instituir a prática moral, assembleias de classe, como um espaço voltado para o diálogo e participação de todos os envolvidos é de grande valia ao contexto escolar, uma vez que esta tem como eixo principal o diálogo, dando possiblidades para que os alunos possam se expressar, resolver conflitos, estabelecer regras a partir do consenso de todos os envolvidos, sentirem-se ouvidos, respeitados, adquirindo confiança e consequentemente desenvolver competências e habilidades, superando suas necessidades educacionais a partir dos laços fortalecidas de amizade, solidariedade e respeito.

Em síntese, trabalhar com assembleia é inserir uma proposta para a formação de indivíduos autônomos e críticos, pois a participação efetiva das decisões que permeiam o universo escolar, desde o planejamento de diferentes propostas a serem desenvolvidas, a elaboração de atividades a serem realizadas pela escola cotidianamente até assuntos relacionados à convivência coletiva, ou seja, os alunos são protagonistas em todo os processos que a escola possibilita.

Por certo, as assembleias
são situações particulares
que podem propiciar esse
autoconhecimento:
quando são convidados a
falar sobre suas próprias
interpretações das
situações que ocorrem no
grupo, os alunos falam de
seus pensamentos e de
seus sentimentos-falam de
si. Sentem-se, portanto,
valorizados, porque
podem opinar, e, mais do
que isso, sentem-se
pertencentes a um grupo.
(TOGNETTA; VINHA, 2007,
p. 139).

Nesse sentido, tendo em consideração os argumentos expostos, convalidamos e concordamos com Tognetta e Vinha no uso das assembleias enquanto possibilidade de suprir no 
aluno o sentimento de pertencimento a um grupo e com isso, satisfazer uma de suas necessidades enquanto ser humano. Maslow (1943) já citava a importância da satisfação das necessidades sociais, do sentir-se participante de um grupo na sociedade como elemento fundamental na busca pela autorrealização. A Hierarquia de Necessidade de Maslow é representada em cinco níveis dispostos em forma de pirâmide e, apresenta a ideia de que as ações humanas são direcionadas para o alcance de objetivos. A base da pirâmide compreende as necessidades fisiológicas e de segurança; o topo da pirâmide é constituído pelas necessidades da busca pela individualização do ser, como as necessidades sociais, de estima e por último, de autorrealização. À vista disso, um dos aspectos necessários para que sejamos felizes é a satisfação da nossa necessidade de pertencimento a um grupo, ou, em outras palavras, de encontrar o nosso lugar na sociedade, enquanto parte significante de um todo maior.

Acreditamos que as assembleias de classe se configuram como um dos caminhos promotores do diálogo na escola, que pode auxiliar na inclusão das diferenças individuais e culturais, pois os professores, enquanto mediadores deste processo podem estimular para que os participantes externem seus sentimentos, suas opiniões e até seus traumas e medos, aprendendo também a ouvir o outro e compreender as consequências de suas ações dentro da escola, tendo em vista um processo de autonomia, respeito e pertencimento ao grupo.

\section{CONSIDERAÇÕES FINAIS}

Tendo em vista as discussões apresentadas resultantes de uma revisão da literatura somada à prática experienciada pelas pesquisadoras, trazemos aqui nossas reflexões sobre o tema proposto com o intuito de incentivar possíveis mecanismos promotores do diálogo e da troca colaborativa nas escolas e instituições de ensino. Não temos a pretensão de esgotar as discussões sobre o assunto e nem acreditamos que a prática das assembleias por si só, sejam capazes de resolver todos os problemas de comunicação tão presentes e constantes no universo educacional.

Contudo, faz-se necessário que propostas sejam feitas para que a escola vá além da formação intelectual dos alunos, possibilitando oportunidades para a formação social e moral, a fim de que estes se tornem cidadãos que sabem viver em sociedade em agem com respeito, valorizando a vida e o próximo. Além disso, devido às carências encontradas em grande parte das escolas e instituições de ensino, acreditamos que seja importante a discussão sobre práticas que não necessitem de um aparato tecnológico para sua implementação ou execução. Ressaltamos que não fazemos nenhuma crítica ao uso das tecnologias da informação e da comunicação com o objetivo de melhorar o sistema educacional, pois certamente muitas ideias de aplicativos, softwares e novas metodologias de ensino podem revolucionar a educação como um todo.

Nosso convite é para refletir sobre a ideia de que nem toda revolução é feita com o auxílio da tecnologia, pois como disse Mahatma Gandhi, "A única revolução possível é dentro de nós". Acreditamos que ensinando valores, a escola pode ajudar na formação de seres humanos, mais do que alunos os quais compreendem a teoria, mas, nem sempre, sabem viver em sociedade, ouvir o outro e respeitar a divergência de opiniões.

Compreendemos a complexidade do assunto e a necessidade de estudos mais aprofundados nesta temática, contudo, esperamos que este trabalho seja um convite à reflexão, a dar voz aos alunos, para que estes possam construir em conjunto com professores e gestores, um ambiente escolar participativo, que valoriza as diferenças, o diálogo e o respeito mútuo.

Mais do que estudantes conformados e apáticos, esperamos promover discussões que resultem em ambientes construtivistas e desenvolvimentistas, que pensam no aluno enquanto ser humano pensante e único, que precisa ser respeitado em sua unicidade, ouvido e, que pode colaborar na construção das regras que governam seu espaço de convivência com os colegas e professores.

\section{REFERÊNCIAS}

ARAÚJO, U. F. Assembleia escolar: um caminho para a resolução de conflitos. São Paulo: Moderna, 2004.

ARAÚJO, U. F. A construção de escolas democráticas: histórias sobre complexidade, mudanças e resistências. São Paulo: Moderna, 2002. 
ARGÜÍs, R. et al. Tutoria: com a palavra, o aluno. Tradução de Fátima Murad. Porto Alegre: Artmed, 2002.

BRUNER, J. S. La Cultura dell'educazione. Milão: Feltrinelli, 1996.

DELORS, J. Educação um tesouro a descobrirrelatório para a UNESCO da Comissão Internacional sobre a Educação para o século XXI. São Paulo: Cortez, 1996.

FREIRE, P. Pedagogia do oprimido. 17. Ed. Rio de Janeiro: Paz e Terra, 1987.

Educação e mudança. 26. ed. Rio de Janeiro: Paz e Terra, 2002.

GARCIA, X. M.; PUIG, J. M. As sete competências básicas para educar em valores. São Paulo: Summus, 2010.

MORENO, C. I. Educar em valores. 3. ed. São Paulo: Paulinas, 2005.

OLIVEIRA, I A.; SANTOS, $T$ R L. A cultura amazônica em práticas pedagógicas de educadores populares. GT Educação Popular, n.6, 2007.

PONTECORVO, C.; AJELLO, A. M.; ZUCCHERMAGLIO, C. Discutindo se aprende: interação social, conhecimento e escola. Porto Alegre: Artmed, 2005.

ROSENBERG, M. B. Comunicação não-violenta: técnicas para aprimorar relacionamentos pessoais e profissionais. 1 ed. São Paulo: Summus, 2006.

SALVADOR, A. D. Métodos e técnicas de pesquisa bibliográfica. Porto Alegre: Sulina, 1991.

TOGNETTA, L. R. P.; VINHA, T. P. Quando a escola é democrática: um olhar sobre a prática das regras e assembleias na escola. 2. ed. Campinas: Mercado das Letras, 2007.

VYGOTSKY, L. S. Storia dello sviluppo delle funzioni psichiche superiori. Firenze: Giunti Barbera, 1974.

VYGOTSKY, L. S. A formação social da mente. São Paulo: Martins Fontes, 1999.

Recebido para publicação em: 24/04/2016

Revisado em: 27/04/2016

Aceito em: 30/04/2016 